\title{
Hearing Loss among Grain Millers in the Informal Sector in Benin
}

\section{Mênonli Adjobimey ${ }^{1,2,3^{*}}{ }^{\mathbb{B}}$, Antoine Vikkey Hinson'1, Rose Mikponhoué1, Eyidi M. Madeleine1, Concheta Tchibozo ${ }^{3}$, Esdras Hountohotegbe1, Paul Ayélo' ${ }^{1}$}

\author{
${ }^{1}$ Research and Education Unit in Occupational Health and Environment FSS, Cotonou, Benin \\ ${ }^{2}$ Occupational Health Service of the National University Hospital of Pneumo-Phtisiology of Cotonou, Cotonou, Benin \\ ${ }^{3}$ Laboratory of Epidemiology of Chronic and Neurological Diseases FSS, Cotonou, Benin \\ Email: menoladjobi@yahoo.fr
}

How to cite this paper: Adjobimey, M., Hinson, A.V., Mikponhoué, R., Madeleine, E.M., Tchibozo, C., Hountohotegbe, E. and Ayélo, P. (2022) Hearing Loss among Grain Millers in the Informal Sector in Benin. Occupational Diseases and Environmental Medicine, 10, 35-47.

https://doi.org/10.4236/odem.2022.101003

Received: October 3, 2021

Accepted: January 2, 2022

Published: January 5, 2022

Copyright $\odot 2022$ by author(s) and Scientific Research Publishing Inc. This work is licensed under the Creative Commons Attribution International License (CC BY 4.0).

http://creativecommons.org/licenses/by/4.0/

\begin{abstract}
Introduction: Noise-induced hearing loss is a preventable health problem worldwide. However, it continues to affect workers especially in the informal sector, due to the lack of medical and environmental monitoring. In Benin, millers are highly exposed. The objective of the study was to assess the hearing health situation of grain millers in the Dantokpa market in 2020. Methods: This was a cross-sectional study that included by exhaustive recruitment 57 millers. The data were collected using a standardized questionnaire followed by blood pressure measurements, noise levels and the performance of audiometries. Descriptive and univariate analysis was performed. Results: The sample consisted only of men. The median age was 25 years with extremes of 18 and 50 years. Noise levels at the workstation $\geq 85 \mathrm{~dB}$ (A) were obtained for $94.74 \%$ of the workers. No worker was wearing hearing protection equipment. The prevalence of hearing loss was $87.72 \%(95 \% \mathrm{CI}=[76.32 \%$; $94.92 \%])$ and that of occupational deafness was $29.82 \%$ (95\% CI $=[18.43 \%$ $43.40 \%]$ ) which was associated with age over 28 and high blood pressure. An awareness campaign with donation of hearing pads was carried out. Conclusion: Hearing loss is important among millers who do not benefit from any supervision because they are in the informal sector. A restructuring of this sector is necessary for the hearing health of workers.
\end{abstract}

\section{Keywords}

Noise, Hearing Loss, Blood Pressure, Millers, Benin

\section{Introduction}

Hearing loss can significantly affect the quality of life of workers and their fami- 
lies, leading to a social handicap [1] [2]. Noise-induced hearing loss is a preventable health problem worldwide [3] [4]. However, it continues to harm workers in several sectors of activity, especially in industrial or artisanal environment [5]. The prevalence of noise-induced hearing loss in industrial settings was 37\% to 59.7\% in America in 2015 [6]; 7\% in China in the automotive industry in 2015 [7]; 58.5\% in Tanzania in a textile industry in 2015 [8]; 26\% in a steel processing plant in Benin [9]. These frequencies, although high, are those of the formal sector where the application of regulations tends to reduce the effects of noise on human health. Workers in the informal sector are exposed uncontrollably to high noise levels. In Benin, epidemiological data relating to hearing loss in grain millers is almost non-existent and yet it is a very useful activity for feeding in the community. In fact, the working conditions in the flour mills expose to several occupational nuisances at the same time: noise, flour dust, chemicals, stress at work, prolonged sitting posture. The objectives of the present study were to: i) identify auditory and extra-auditory symptoms related to noise exposure; ii) measure noise level at the different workstations; iii) determine the prevalence of hearing loss; iv) implement prevention strategies among grain millers in the Dantokpa market.

\section{Materials and Methods}

\subsection{Study Design}

This was a descriptive cross-sectional study that took place from August 1 to September 31, 2020.

\subsection{Study Framework}

The study took place at Dantokpa market, the largest market in Benin, and precisely at the workstations of the grain millers. The millers work in rooms of $8 \mathrm{~m}^{2}$, most of which have only one door for ventilation. Each room has two to four machines with independent operation. Many of the workers are day laborers for the owners of the millstones.

\subsection{Study Population and Sampling}

The study population was made up of millers from the Dantopka market with at least one year of seniority in the activity. An exhaustive recruitment has been carried out. The millers with a hearing history before taking up the post as well as those who did not perform an audiometry were excluded from the study.

\subsection{Collection of Data}

Data collection was carried out through a "face-to-face" interview. The data were collected using a standardized form. The information provided related to socio-demographic, professional and clinical characteristics.

The noise level was measured using a sound level meter at all stations. The sound level meter was placed at each workstation at the actual time of a grain 
grinding activity, with the mill running. Instantaneous measurements were made over a period of $5 \mathrm{~mm}$. The reading was made directly on the screen of the device.

Audiometry was performed using an audiometer calibrated to millers outside their workplace at the National Hospital Center for Pneumo-phtisiology after an otoscopic examination and after an auditory rest of 48 hours and before taking up the post. The ENT examination was performed by a physician using an otoscope and specula. Both ears were examined. The clinical features sought were: earwax plug in the ear canal, tympanic perforation, ear discharge.

The millers with a plug of earwax were invited to a washing of the auditory canal before the audiometry.

When the ENT examination is normal, audiometry can be performed. The audiometry was not performed in a soundproof room but in a room isolated from other hospital activities. A mechanical audiometer associated with a headset was used. The evaluation of the hearing loss was performed at frequencies of $500 \mathrm{~Hz}, 1000 \mathrm{~Hz}$ and $4000 \mathrm{~Hz}$. The hearing loss is mentioned with the red prn for the right ear and in blue for the left ear. The hearing loss was calculated by $[($ lost $500 \mathrm{~Hz})+($ lost $1000 \mathrm{~Hz})+($ lost $2000 \mathrm{~Hz})+($ lost $4000 \mathrm{~Hz})] / 4$. Audiometry results were interpreted by an occupational physician and an ENT specialist.

\subsection{Variables of Interest}

Hearing loss has been defined according to the classification of the International Bureau of Audio phonology (BIAP). We distinguish according to the level of the average tonal hearing loss calculated by the arithmetic mean of the deficits at the frequencies of $500 \mathrm{~Hz}, 1000 \mathrm{hz}, 2000 \mathrm{hz}$ and $4000 \mathrm{hz}$, normal hearing: $\leq 20 \mathrm{~dB}$; mild deafness: 21 to $40 \mathrm{~dB}$; moderate deafness: 41 to $70 \mathrm{~dB}$; severe deafness: 71 to 90dB; profound deafness: $91-119 \mathrm{~dB}$ and total deafness or cophosis: $\geq 120 \mathrm{~dB}$. Occupational deafness was defined according to Decree 2013-50 of February 11, 2013 establishing the list of occupational diseases in the Republic of Benin by a bilateral hearing loss greater than or equal to $35 \mathrm{~dB}$ in the better ear in a worker exposed to noise with a seniority of at least one year. The noise level was classified according to WHO standards due to the absence of any normative document on the subject in the Republic of Benin. The first exposure threshold for preventive action is $80 \mathrm{~dB}$ (A) for 8 hours (alert threshold). The noise exposure threshold that must trigger corrective measures by the employer (noise reduction at the source or provision of hearing protection) is $85 \mathrm{~dB}$ (danger threshold).

\subsection{Data Analysis}

Data analysis was performed with Epi-info 7.2.6 software. Proportions were calculated for qualitative variables and means with standard deviations for quantitative variables. A univariate analysis was used to search for factors associated with occupational deafness using the Chi 2 test at a significance level of $p<0.05$, so a crude odds ratio was performed. 


\subsection{Ethical Considerations}

Permission was obtained from Dantopka's market managers and informed consent was obtained from participants. Data were collected with respect to confidentiality and human rights. Travel of participants was at the expense of the research team. Data management and use was done anonymously.

\section{Results}

\subsection{Socio-Demographic and Professional Characteristics}

A total of 57 millers, all men, participated in the study out of the 64 identified. The reasons for non-participation were: 3 did not present in the hospital for the completion of the ENT consultation and audiometry, 2 had a history of hearing since childhood and 1 had a profound hearing loss in one ear prior to entry into the sector. Their median age was 25 years with extremes of 18 and 50 years, distributed as follows: 64.91\% [18 - 28[ years, 21.05\% [28 - 38[; 12.28\% [38 48 [ and $1.75 \%$ age $\geq 48$ years. Among the millers $42.11 \%$ were in a couple, $52.63 \%$ were single and $5.26 \%$ were widowed/divorced. At the professional level, $57.89 \%$ had a seniority in the job of more than 2 years, there were 11 bosses versus 46 apprentices. The average daily working time was more than 12 hours for $45.61 \%$ and $42.11 \%$ had a daily income of less than 4 US dollars. Only 5.26\% were engaged in extra-occupational activities involving noise exposure at the same time. The instantaneous measurement of noise at the different workstations allowed us to classify the millers by level of exposure as follows: $5.26 \%$ exposed to less than $80 \mathrm{~dB}(\mathrm{~A}) ; 26.32 \%$ exposed to between 90 and $100 \mathrm{~dB}(\mathrm{~A})$ and $68.42 \%$ exposed to more than $100 \mathrm{~dB}(\mathrm{~A})$. Table 1 exposes socio-demographic and professional characteristics of the informal cereal millers. None of the 57 millers had hearing personal protection equipment (PPE) available at the time of work. Figure 1 shows the working conditions at the grain crushing site. All the workers recognized permanent exposure to noise and $45.61 \%$ had a good knowledge of the auditory effects of noise.

\subsection{Clinical Symptomatology}

Conversation disturbance affected a total of 10 out of 57 millers and concerned the raising of the voice by the miller himself or his entourage and the increase in volume of the devices. The most frequent hearing symptoms were the sensation of auditory fatigue (89.47\%); tinnitus (73.68\%) such as ringing and whistling in the ears. On the extra-auditory level, the most represented symptoms were: headaches (71.93\%); irritability (64.91\%); palpitations (57.89\%) and dizziness (56.14\%). An increase in blood pressure was noted, greater than or equal to $140 / 90 \mathrm{mmHg}$ in $43.86 \%$. Table 2 describes the clinical symptomatology related to hearing loss in cereal millers.

\subsection{Prevalence of Hearing Loss and Associated Factors}

The prevalence of deafness was $87.72 \%$ 95\% CI [76.32\%; 94.92\%] with $24.56 \%$ 
Table 1. Socio-demographic characteristics of cereal millers, Dantokpa Cotonou $(\mathrm{N}=$ 57).

\begin{tabular}{|c|c|c|}
\hline & Effectif $(\mathrm{N})$ & Fréquence (\%) \\
\hline \multicolumn{3}{|l|}{ Age (years) } \\
\hline$[18-28]$ & 37 & 64.91 \\
\hline$[28-38]$ & 12 & 21.05 \\
\hline$[38-48]$ & 7 & 12.28 \\
\hline$>48$ & 1 & 1.75 \\
\hline \multicolumn{3}{|l|}{ Marital status } \\
\hline Single & 30 & 52.63 \\
\hline In couple & 24 & 42.11 \\
\hline Divorced & 2 & 3.51 \\
\hline widowed & 1 & 1.75 \\
\hline \multicolumn{3}{|l|}{ Level of education } \\
\hline Illiterate & 15 & 26.32 \\
\hline Primary & 25 & 43.86 \\
\hline Secondary & 15 & 26.32 \\
\hline Higher & 2 & 3.51 \\
\hline \multicolumn{3}{|l|}{ Daily income (dollars US) } \\
\hline$[1.78-3.56[$ & 24 & 42.11 \\
\hline$\geq 3.56$ & 36 & 57.89 \\
\hline \multicolumn{3}{|l|}{ BMI } \\
\hline Normal & 40 & 70.18 \\
\hline Obese & 3 & 5.26 \\
\hline Overweight & 14 & 24.56 \\
\hline \multicolumn{3}{|c|}{ Length of time in position (years) } \\
\hline$[0-2[$ & 24 & 42.11 \\
\hline$\geq 2$ & 33 & 57.89 \\
\hline \multicolumn{3}{|c|}{ Noise Exposure level at the workplace } \\
\hline Less than $80 \mathrm{~dB}(\mathrm{~A})$ & 3 & 5.26 \\
\hline Between 90 and $100 \mathrm{~dB}(\mathrm{~A})$ & 15 & 26.32 \\
\hline More than $100 \mathrm{~dB}$ & 39 & 68.42 \\
\hline \multicolumn{3}{|c|}{ Extra-occupational noise exposure } \\
\hline Yes & 3 & 5.26 \\
\hline No & 54 & 94.74 \\
\hline
\end{tabular}




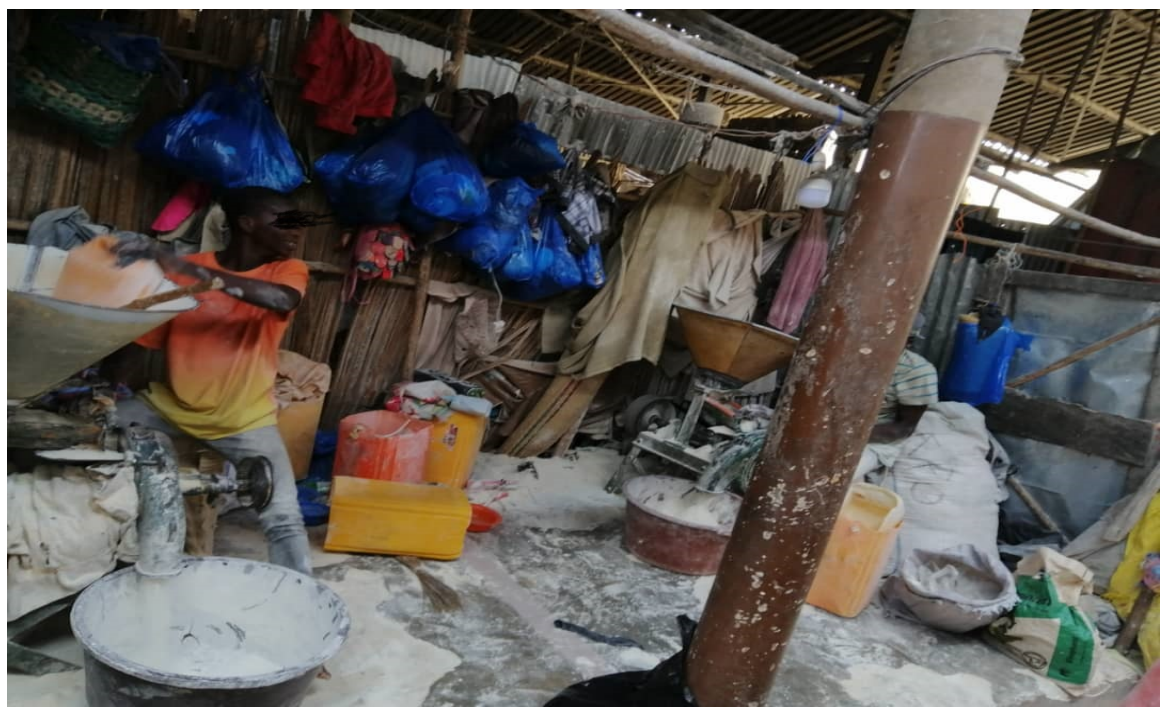

Figure 1. Working conditions of the grain millers at Dantokpa Market, Cotonou, Benin, 2020eeWW.

Table 2. Distribution of cereal millers according to auditory and extra-auditory clinical symptoms, Dantokpa Cotonou; $(\mathrm{N}=57)$.

\begin{tabular}{|c|c|c|}
\hline & Number (n) & Frequency (\%) \\
\hline \multicolumn{3}{|l|}{ Communication disorders } \\
\hline Personal Voice Elevation & 8 & 14.03 \\
\hline Ask the entourage to speak loudly & 10 & 17.54 \\
\hline Increase in device volume & 2 & 3.5 \\
\hline \multicolumn{3}{|l|}{ Auditory symptoms } \\
\hline Ringing in the ears & 41 & 71.93 \\
\hline \multicolumn{3}{|l|}{ Whistling } \\
\hline Tinnitus & 42 & 73.68 \\
\hline Sensation of hearing loss & 17 & 28.82 \\
\hline Feeling of hearing fatigue & 51 & 89.47 \\
\hline \multicolumn{3}{|l|}{ Extra-auditory symptoms } \\
\hline Headache & 43 & 71.93 \\
\hline Irritability & 37 & 64.91 \\
\hline Depression & 9 & 15.79 \\
\hline Sleeping troubles & 27 & 47.37 \\
\hline Concentration disturbance & 11 & 19.30 \\
\hline Anxiety & 26 & 45.61 \\
\hline Dizziness & 32 & 56.14 \\
\hline Palpitations & 33 & 57.89 \\
\hline Perception of stress & 12 & 21.05 \\
\hline
\end{tabular}


moderate deafness and that of occupational deafness was $29.82 \% 95 \%$ CI [ $18.43 \%$ - 43.40\%]. Factors associated with occupational deafness were age greater than 28 years $\left(\mathrm{OR}_{\mathrm{b}}=9.6 ; 95 \% \mathrm{CI}\right.$ [2.62-35.21], $\left.\mathrm{p}=0.0002\right)$ and high blood pressure $\left(\mathrm{OR}_{\mathrm{b}}=4.98 ; 95 \% \mathrm{CI}[1.45-17.14], \mathrm{p}=0.008\right)$. Table 3 and Table 4 present prevalence and factors associated with hearing loss.

Table 3. Distribution of cereal millers according to the degree of hearing loss, Dantokpa, Cotonou; $(\mathrm{N}=57)$.

Number (n) Frequency (\%)

\section{BIAT classification}

Normal hearing: $\leq 20 \mathrm{~dB}(\mathrm{~A})$

Mild deafness: [21 - 40] dB (A)

Moderate deafness: [41 - 70] dB (A)

7

36

14

Classification according to intervention threshold

No intervention: $<25 \mathrm{~dB}(\mathrm{~A})$

Action on the environment: [25 - 35[ dB (A)

Worker withdrawal: $\geq 35 \mathrm{~dB}$ (A)

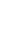

12.28

63.16

24.56

24.56

Table 4. Associated factors of hearing loss in cereal millers Dantokpa, Cotonou; $(\mathrm{N}=57)$.

\begin{tabular}{|c|c|c|c|c|c|c|}
\hline & \multirow{2}{*}{$\mathbf{N}$} & \multicolumn{2}{|c|}{ Hearing loss } & \multirow{2}{*}{$\mathrm{ORb}$} & \multirow{2}{*}{ [IC95\%] } & \multirow{2}{*}{$\mathrm{p}$} \\
\hline & & $\mathrm{n}$ & $\%$ & & & \\
\hline Age (years) & & & & & & 0.0002 \\
\hline$[18-28[$ & 37 & 5 & 13.51 & 1 & Reference & \\
\hline$\geq 28$ & 20 & 12 & 60.00 & 9.60 & {$[2.62-35.21]$} & \\
\hline Matrimonial status & & & & & & 0.280 \\
\hline In couple & 24 & 9 & 37.50 & 1 & Reference & \\
\hline Single/divorced/widowed & 33 & 8 & 24.24 & 0.53 & {$[0.16-1.68]$} & \\
\hline Instruction level & & & & & & 0.755 \\
\hline Scolarized & 42 & 13 & 88.1 & 1 & & \\
\hline Never scolarized & 15 & 4 & 86.67 & 0.81 & {$[0.22-3.03]$} & \\
\hline Salary /day & & & & & & 0.205 \\
\hline$[\geq 3.56$ & 33 & 12 & 84.85 & 1 & Reference & \\
\hline$[1.78-3.56[$ & 24 & 05 & 20.83 & 0.57 & {$[0.23-1.41]$} & \\
\hline IMC & & & & & & 0.063 \\
\hline Normal & 40 & 9 & 47.06 & 1 & Reference & \\
\hline Abnormal & 17 & 8 & 22.50 & 0.32 & {$[0.09-1.09]$} & \\
\hline Type of worker & & & & & & 0.905 \\
\hline Apprentices & 46 & 13 & 28.26 & 1 & Reference & \\
\hline Boss & 11 & 04 & 36.36 & 1.08 & {$[0.29-4.02]$} & \\
\hline
\end{tabular}




\begin{tabular}{lcccccc} 
Continued & & & & & & \\
\hline $\begin{array}{l}\text { Seniority } \\
>1 \text { year }\end{array}$ & 56 & 17 & 30.36 & - & - & 0.511 \\
$\quad \leq 1$ year & 1 & 0 & 0.00 & - & - & \\
Working hours week & & & & & & 1.000 \\
$\quad>6$ hours & 56 & 17 & 30.36 & - & - & \\
$\quad \leq 6$ hours & 1 & 0 & 0.00 & - & - & \\
Hypertension & & & & & & \\
$\quad$ No & 32 & 5 & 15.63 & 1 & Reference & \\
$\quad$ Yes & 25 & 12 & 48.00 & 4.98 & {$[1.45-17.14]$} & \\
\hline
\end{tabular}

\subsection{Interventions}

Following the results, several corrective actions were carried out: an awareness campaign on the hearing risk linked to noise, a punctual distribution of anti-noise wadding, a recommendation for regular breaks and a limitation of the daily working time. Millers suffering from occupational deafness were referred to the ENT specialist for better care. An invitation to the millers to organize themselves in cooperatives to facilitate their medical follow-up was proposed.

\section{Discussion}

Prevention of deafness in the informal work environment is poorly covered, unlike in the formal sector. To our knowledge, this is the first study in the country to assess deafness in informal millers. The strengths of the study lie in its comprehensiveness and the use of appropriate tools to assess noise and hearing loss. An important limitation of the study is that in the results, the effect of age on the hearing loss of individuals is not controlled for and is confounded by the effect of noise. Also, the realization of the audiometry did not respect the minimum 72 hours of cessation of exposure to noise required by the Beninese regulation before affirming the diagnosis of occupational deafness. This is due to the daily status of the workers and the loss of income for the millers. However, the millers with suspected occupational deafness were sent to the ENT specialist for additional voluntary exploration. Unfortunately, due to low income, only one miller was able to attend the ENT consultation and the diagnosis was confirmed. It should be noted, however, that several authors in the literature recommend a duration of 48 hours for the cessation of exposure to noise.

Comparison of the results with those of other authors is sometimes difficult because of occupational variability, the existence of few data in the informal sector and the use of different measurement tools.

Our study showed high noise levels at all workstations compared to the standards. These results are similar to those observed in Tunisia in workers exposed daily to noise throughout the production line of flour and semolina from reception, cleaning, milling of wheat, sieving of crushed wheat and its grading in dif- 
ferent dimensions to the storage of finished products [10]. In Benin, in another informal sector among tinsmiths, an average noise level of $90.6 \pm 4.8 \mathrm{~dB}$ (A)was found [11].

The prevalence of hearing loss and occupational deafness in particular is very high among millers who are young workers with less than 5 years of service for the vast majority but who did not use hearing protection equipment. The prevalence of hearing loss is higher than that observed in several studies conducted in the formal sector: $24 \%$ in oil and gas extraction in New England, USA; $58.5 \%$ in Tanzania in 2014 among workers in a textile industry [8]; in a steel production plant in Benin [9]; the same is true for occupational deafness with only $5.8 \%$ in a sawmill and carpentry in Benin [12].

On the other hand, in the informal sector, our results corroborate those of other authors such as Ayélo et al. who found a prevalence of $79.3 \%$ of hearing loss among tinsmiths with an average duration of exposure to noise of 13 years \pm 10 months and not wearing hearing PPE [11].

The prevalence of hearing loss therefore varies from country to country, from industry to industry and with the use of hearing protection equipment [13] [14]. Indeed, the absence of hearing protection equipment exposes millers to very high noise levels with the risk of hearing accidents.

The association found between age and occupational deafness corroborates several findings in the literature [15] [16]. Indeed, the older the age, the greater the risk of hearing loss if the subject is still exposed to noise. What is particular in the present study is the young miller who is, however, associated with occupational hearing loss. The association found between high blood pressure and occupational deafness is justified. Indeed, several authors have shown the risk of occurrence of arterial hypertension or a cardiovascular event in people usually exposed to noise [17] [18] [19] and therefore showed an association between noise-related hearing loss and cardiovascular disorders [7] [20].

Noise-induced hearing loss can be prevented if the right preventive measures are taken. Several prevention strategies are described in the literature depending on the intensity of the exposure, the exposing equipment, the duration of the exposure and the sector of activity [21] [22]. The preventive measures implemented in this study, such as awareness of hearing risks and distribution of hearing individual equipment, remain ad hoc and must be reinforced by a formal organization of the sector and the implementation of an environmental and clinical monitoring program for millers.

\section{Conclusion}

The prevalence of bilateral hearing loss among millers in the Dantokpa market is very high, as is the prevalence of occupational deafness. The implementation of a permanent support program for the improvement of working conditions as well as the medical follow-up of these informal sector workers is necessary to limit the consequences of permanent and prolonged exposure to noise due to an ac- 
tivity that is vital for the community

\section{Thanks}

Our thanks go to the managers of the Dantokpa Market and to the millers for giving us the opportunity to carry out this work.

\section{Conflicts of Interest}

The authors declare no conflicts of interest regarding the publication of this paper.

\section{References}

[1] Sheppard, A., Ralli, M., Gilardi, A. and Salvi, R. (2020) Occupational Noise: Auditory and Non-Auditory Consequences. International Journal of Environmental Research and Public Health, 17, Article No. 8963. https://doi.org/10.3390/ijerph17238963

[2] Deng, X.F., Shi, G.Q., Guo, L.L., Zhu, C.A. and Chen, Y.J. (2019) Analysis on Risk Factors of Depressive Symptoms in Occupational Noise-Induced Hearing Loss Patients: A Cross-Sectional Study. Noise and Health, 21, 17-24. https://doi.org/10.4103/nah.NAH 1618

[3] Lie, A., Skogstad, M., Johannessen, H.A., Tynes, T., Mehlum, I.S., Nordby, K.C., et al. (2016) Occupational Noise Exposure and Hearing: A Systematic Review. International Archives of Occupational and Environmental Health, 89, 351-372. https://doi.org/10.1007/s00420-015-1083-5

[4] Zhou, J., Shi, Z., Zhou, L., Hu, Y. and Zhang, M. (2020) Occupational Noise-Induced Hearing Loss in China: A Systematic Review and Meta-Analysis. BMJ Open, 10, Article ID: e039576. https://doi.org/10.1136/bmjopen-2020-039576

[5] Nelson, D.I., Nelson, R.Y., Concha-Barrientos, M. and Fingerhut, M. (2005) The Global Burden of Occupational Noise-Induced Hearing Loss. American Journal of Industrial Medicine, 48, 446-458. https://doi.org/10.1002/ajim.20223

[6] Rabinowitz, P.M. (2000) Noise-Induced Hearing Loss. American Family Physician, 61, 2749-2756.

[7] Kuang, D., Yu, Y.Y. and Tu, C. (2019) Bilateral High-Frequency Hearing Loss Is Associated with Elevated Blood Pressure and Increased Hypertension Risk in Occupational Noise Exposed Workers. PLoS ONE, 14, Article ID: e0222135. https://doi.org/10.1371/journal.pone.0222135

[8] Abraham, Z.S., Massawe, E., Ntunaguzi, D., Mawala, S. and Kahinga, A.A. (2019) Prevalence of Noise-Induced Hearing Loss among Textile Industry Workers in Dar es Salaam, Tanzania. Annals of Global Health, 85, 85. https://doi.org/10.5334/aogh.2352

[9] Hinson, A., Lawin, H., Gounongbe, F., Aguemon, B. and Gnonlonfoun, D. (2017) Évaluation des nuisances sonores chez les travailleurs d'une société de production d'acier au Bénin. Camip. Info, 2, 1-4.

[10] Majdoub, I., Hajjaji, M., Kotti, N., Kchaou, A. and Masmoudi, M.L. (2016) Les facteurs prédictifs de la surdité professionnelle induite par le bruit. Rev tunisienne Pathol Prof L'Environnement, 4, 43-46.

[11] Ayelo, A.P., Aguemon, B., Hinson, A.V., Yedomon, B. and Afokpa, K. (2018) Atteintes auditives chez les ferblantiers du secteur informel à Cotonou. Archives des 
Maladies Professionnelles et de P Environnement, 79, 244. https://doi.org/10.1016/j.admp.2018.03.054

[12] Gounongbe, A.C.F., Assavedo, C.R.A., Abouki, C.O.A., Hinson, A.V., Dovonou, C.A., Flatin, M., et al. (2018) Evaluation des facteurs de risque chez les travailleurs du bois de Parakou. Journal de la Recherche Scientifique de PUniversité de Lomé, 20, 2413-2354.

[13] Edelson, J., Neitzel, R., Meischke, H., Daniell, W., Sheppard, L., Stover, B., et al. (2009) Predictors of Hearing Protection Use in Construction Workers. Annals of Occupational Hygiene, 53, 605-615.

[14] Sbihi, H., Teschke, K., MacNab, Y.C. and Davies, H.W. (2010) An Investigation of the Adjustment of Retrospective Noise Exposure for Use of Hearing Protection Devices. Annals of Occupational Hygiene, 54, 329-339.

[15] Keppler, H., Dhooge, I. and Vinck, B. (2015) Hearing in Young Adults. Part I: The Effects of Attitudes and Beliefs toward Noise, Hearing Loss, and Hearing Protector Devices. Noise Health, 17, 237-244. https://doi.org/10.4103/1463-1741.165024

[16] Daniel, E. (2007) Noise and Hearing Loss: A Review. Journal of School Health, 77, 225-231. https://doi.org/10.1111/j.1746-1561.2007.00197.x

[17] Zhao, Y., Zhang, S. and Selvin, S. (1991) A Dose Response Relation for Noise Induced Hypertension. British Journal of Industrial Medicine, 48, 179-184.

https://doi.org/10.1136/oem.48.3.179

[18] Verbeek, J., van Dijk, F. and de Vries, F. (1987) Non-Auditory Effects of Noise in Industry. IV. A Field Study on Industrial Noise and Blood Pressure. International Archives of Occupational and Environmental Health, 59, 51-54. https://doi.org/10.1007/BF00377678

[19] Eriksson, H.P., Andersson, E., Schiöler, L., Söderberg, M., Sjöström, M., Rosengren, A., et al. (2018) Longitudinal Study of Occupational Noise Exposure and Joint Effects with Job Strain and Risk for Coronary Heart Disease and Stroke in Swedish men. BMJ Open, 8, Article ID: e019160. https://doi.org/10.1136/bmjopen-2017-019160

[20] Sbihi, H., Demers, P. and Davies, H. (2008) Hypertension in Noise-Exposed Sawmill Workers: A Cohort Study. Occupational and Environmental Medicine, 65, 643 646. https://doi.org/10.1136/oem.2007.035709

[21] Verbeek, J.H., Kateman, E., Morata, T.C., Dreschler, W.A. and Mischke, C. (2012) Interventions to Prevent Occupational Noise-Induced Hearing Loss. Cochrane Database of Systematic Reviews, No. 10, Article No. CD006396.

https://doi.org/10.1002/14651858.CD006396.pub3

[22] Tikka, C., Verbeek, J.H., Kateman, E., Morata, T.C., Dreschler, W.A. and Ferrite, S. (2017) Interventions to Prevent Occupational Noise-Induced Hearing Loss. Cochrane Database of Systematic Reviews, No. 7, Article No. CD006396. https://doi.org/10.1002/14651858.CD006396.pub4 


\section{Appendix}

\section{$\mathrm{N}^{\bullet}$ Questions}

\section{General Information}

Q1 Record number

Q2 Date of registration

Q3 Personnel number

Q4 Phone number

\section{Socio-demographic characteristics}

Q5 Age (Years)

Q6 Sex

Q7 Nationality

Q8 Marital status

Q13 Level of education

\section{Work center information}

Q14 How many years have you been working in the milling factory of Dantokpa market?

Q15 What is your professional status?

Q16 How many hours do you work a day?

Q17 Noise level measurement at the station

\section{Codes}

Answer

Date of registration in the study

Give the participant's registration number in the structure

Number of years completed

Female $=0 ;$ Male $=1$

Beninese $=0$; Others $=1($ Specify ...)

Single $=0$; Couple $=1$;

Divorced $=2$; Widowed $=3$

Never attended $=0$; Literate $=1$;

Primary $=2$; Secondary $=3$; Higher $=4$

Specify the number of years of exercise; 999 if not applicable

Mill owner $=0$

Serving a leader $=1$

$1-2$ years $=0$

More than 2 years $=1$

Inf $85 \mathrm{~dB}=0$

$85-90 \mathrm{~dB}=1$

Sup $90 \mathrm{~dB}=2$

Q18 Do you have personal protective equipment (PPE) against noise? No $=0$; Yes $=1$

Q19 If yes, name them and show them

Q20 Does your job require you to be in constant noise all day?

No $=0 ;$ Yes $=1$

Q21 Do you take a break at your workstation?

No $=0 ;$ Yes $=1$

Q22 If so, what do you do during the break?

You stay at the station $=1$

You are leaving the position $=2$ Other to be specified $=3$

Do you have any activities outside of milling that expose you to noise?

No $=0 ;$ Yes $=1$

Non-smoker $=0$; Current smoker $=1$;

Ex-smoker $=2$; Passive smoker $=3$ 


\section{Continued}

Q25 Do you have an ENT history before starting to work in the No =0; Yes =1 milling industry? (otitis, tympanic perforation, trauma)

\section{Complaints}

Q26 Do you speak normally at work to make yourself heard?

Q27 Do you know the health effects of noise?
No $=0 ;$ Yes $=1$

Acute cough $=0$; Chronic dry cough $=1$;

Chronic productive cough $=2$; Not

applicable $=9$

After 8 hours of work do you experience the following No=0; Yes = 1 symptoms?

Q28 Headaches

$$
\begin{aligned}
& \text { No }=0 ; \text { Yes }=1 \\
& \text { No }=0 ; \text { Yes }=1 \\
& \text { No }=0 ; \text { Yes }=1 \\
& \text { No }=0 ; \text { Yes }=1 \\
& \text { No }=0 ; \text { Yes }=1 \\
& \text { No }=0 ; \text { Yes }=1 \\
& \text { No }=0 ; \text { Yes }=1 \\
& \text { No }=0 ; \text { Yes }=1 \\
& \text { No }=0 ; \text { Yes }=1 \\
& \text { No }=0 ; \text { Yes }=1 \\
& \text { No }=0 ; \text { Yes }=1
\end{aligned}
$$

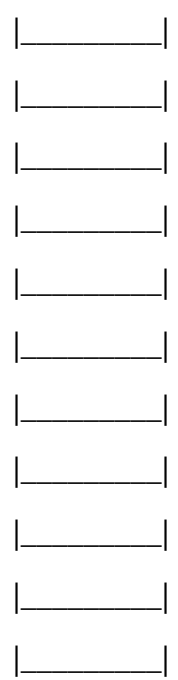

\section{General review}

Q39 Weight (kgs)

Q40 Size (cm)

Q41 Body mass index $\left(\mathrm{kg} / \mathrm{m}^{2}\right)$

Q42 Systolic blood pressure ( $\mathrm{mmHg}$ )

Q43 Diastolic blood pressure ( $\mathrm{mmHg}$ )

Physical examination

Q44 Otoscopic examination

Normal $=0 ;$ Abnormal $=1$ (discharge, inflamed EAC, AOM, perforated eardrum) 